\title{
Crash Analysis of Aircraft Nose Prototype
}

\author{
Adeeba Shaheen, Akash Deep Sinha
}

\begin{abstract}
This paper presents the comparison of structural deformation of generic metals and the new age composite materials on the aircraft nose during a crash. The analysis is conducted to be able to make more educated predictions of the internal structure damage caused when the airplane has a head on collision with a vertical obstacle (buildings) or when affected by a bird strike. Two nose profiles widely seen nowadays are spherically blunted tangent ogive and elliptical. These nose cones have been designed based on model to prototype ratio on $N X$ CAD. CFD has been performed on the nose designs and solved on ANSYS Fluent for flow visualizations. Materials like Aluminum alloy (which is still widely used in fuselage frames) and Carbon Fiber Reinforced Polymer with epoxy resins, have been applied to the CAD models. These were analyzed for stress, strain and deformation on ANSYS 18.1 by simulating the crash of the nose on a thick structural steel plate. After the analysis, it was inferred that the elliptical nose made of Carbon Fiber Reinforced Polymer has less structural deformation on being crashed.
\end{abstract}

Keywords: Aircraft Nose, Aluminum alloy, Carbon fiber reinforced polymer, Explicit Dynamics, Finite Element Analysis

\section{INTRODUCTION:}

Although flying may be the safest mode of transit, accidents could occur through involvement of humans, because of mechanical failure, or due to any sort of crime[22]. Aviation Accident Analysis is usually performed to determine the reasons of an accident. The design of the nose cone of aircraft is such that it can move through a compressible fluid. The significant problem is the determination of the nose cone's geometric shape and the material to be used for optimum performance. Such tasks require a solid shape which only undergo minimal resistance. The nose tip is found at the foremost part of the aircraft which has a huge aerodynamic effect by reduction of drag on the complete aircraft. It is also the housing for radars and other communicative systems and servomotors. As they are a housing to such sensitive systems, they are made from specific materials like fiberglass, quartz, honeycomb, chemical resins and foam cores. Aircraft testing measures have changed drastically over the decade. Rigorous tests by the best companies are carried out to ensure a safe flight. From wing bending tests to simulating bird strikes for evaluating engine damage, the aviation industry constantly keeps getting its game better by practicing new methodologies.

Revised Manuscript Received on July 10, 2020.

* Correspondence Author

Adeeba Shaheen*, Mechanical Engineering Department, SIT, Symbiosis International (Deemed) University, Pune, India. Email: adeeba.shaheen@sitpune.edu.in

Akash Deep Sinha, Mechanical Engineering Department, SIT, Symbiosis International (Deemed) University, Pune, India. Email: akash.sinha@sitpune.edu.in

(C) The Authors. Published by Blue Eyes Intelligence Engineering and Sciences Publication (BEIESP). This is an open access article under the CC BY-NC-ND license (http://creativecommons.org/licenses/by-nc-nd/4.0/)
For example, Bombardier has a non-destructive ground testing facility or an iron bird where the simulation uses all the aircraft systems layouts to fly different places and to study structural issues in an aircraft without having to assemble and fly an aircraft in reality. A FEM model of aircraft was analyzed in LS Dyna for a vertical drop test at $30 \mathrm{ft} / \mathrm{s}$. It was to study the impact of the occupants and the structures [4]. Other new materials such as composites and alloys were also used, including titanium, graphite, and fiberglass, but only in very small quantities. Aluminum was used everywhere from the fuselage to main engine components. But a standard jet built today is as little as $20 \%$ pure aluminum. Most of the non-critical structural material paneling and aesthetic interiors - now consist of even lighter-weight carbon fiber reinforced polymers (CFRPs) and honeycomb materials. Whereas, for engine parts and critical components, there is a simultaneous push for lower weight and higher temperature resistance for better fuel efficiency, bringing new or previously impractical-tomachine metals into the aerospace material mix. New crash analysis codes have been developed just to help us with the reasoning of accident analysis. Mechalog, Radioss Crash Analysis code has now developed a substitute for carbon fiber of the aerospace grade that could be used in race cars [2].The impact energy absorption tool is not so widely used for composites in race cars [2]. Complex failure modes are seen in composites in comparison to the metals. LS Dyna and PAM Crash are also highly unstable when it comes to predicting the crack tracks in a composite material [2]. Fiber metal laminates have less moisture absorbing capacity than carbon epoxy composites due to its metallic barriers [5] They have great stiffness to weight ratio, less fatigue and resistant to corrosion [5]. The metal layer in fiber metal laminates helps in increasing impact property without fatigue cracks. A number of fiber metal laminates of aluminium/ boron titanium/ carbon/epoxy can be developed for better properties. Composites have higher energy absorbing capabilities although it does not possess aluminium's property of ductility. Many new materials like composite metal hybrids are now being tested.

\section{PROBLEM IDENTIFICATION}

None of the research papers talk about the importance of the nose cone in an aircraft. Landing gears have been considered significant in crash landings but the nose is hardly studied. There has been not any significant contribution in the study of the crash impact to the nose structure of the aircraft and the communication systems that it houses. Composite structures have been tested as materials on UTMs but not tested on the noses of aircraft prototypes.

Published By:

Blue Eyes Intelligence Engineering

Retrieval Number: F1360089620/2020@BEIESP

DOI: 10.35940/ijeat.F1360.089620

Journal Website: www.ijeat.org

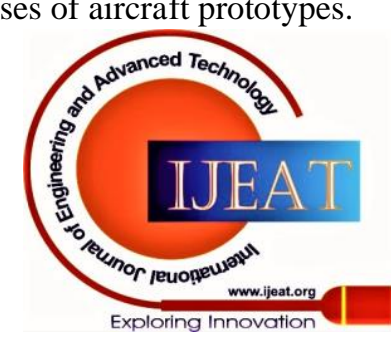


CFD has been performed on noses which are only conic in shape. The materials that are used to study the noses in static conditions are all metals like aluminium and titanium. One of the reasons why composite structures and metal sandwich laminates are still not used in the aircraft structures is because of the lack of development in computer aided engineering solutions. The ones in implementation are mostly for metallic materials and they differ a lot from composites. Reducing the weight of airplanes is an efficient way to improve their performance. In case of an aircraft, the first area of impact during a crash into a building or a bird strike is usually the nose. The impact then resonates in the fuselage which causes widespread damage. Since, the nose of an aircraft is a very crucial part of a commercial airplane, various materials and shapes should be tested to check for it crashworthiness. Composites happen to be more stiff, eliminate residual stresses and less prone to fatigue fractures. Thus, this report will explore the study of comparison between a generic metallic nose and a composite nose.

\section{METHODOLOGY}

\section{A. Modelling and Meshing:}

- Data collected of the nose cone profiles from the research papers.

- Model to prototype ratio calculated for simulation.

- A structural steel plate will be developed that will pose as a concrete structure.

- Modelling of the prototype noses based on the ratio to be developed on a CAD software (NX CAD)

\section{B. Computational fluid dynamics:}

- The velocity given to the nose will be in accordance with the scaled prototype based on the model to prototype ratio.

- To validate the designs and check the drag coefficients, CFD will performed on the nose profiles ANSYS Fluent.

\section{Explicit Dynamics}

- Two materials are chosen to show the comparison between the deformations on the noses.

- $\quad$ By keeping the plate fixed and giving a velocity to the nose at atmospheric pressure, the nose cone will be made to crash the plate and results will be noted and discussed.

\section{MODELLING AND MESHING}

The nose of commercial airplanes are considered which are subsonic or transonic ( $<$ or $=$ Mach 1 ) in nature. Mach number is the ratio of the flow velocity past a body to the speed of sound. Blunt nose profiles are generally applied in commercial aircrafts. Airplanes with rounded nose are able to create a suction on the fuselage which pulls the air around it. Such airplanes during flight, push the air in the front which rolls over the fuselage with less resistance. This creates a suction which then guides the air.

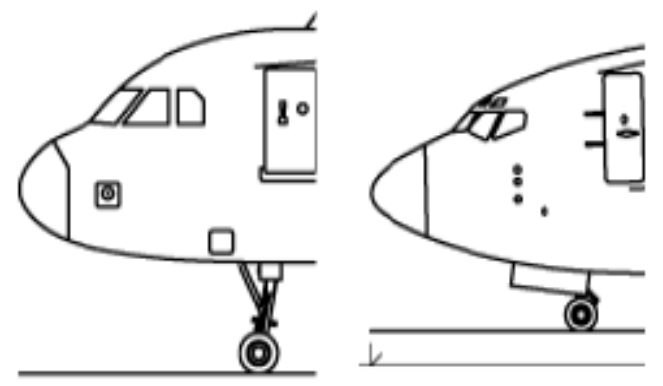

Fig. 1 Airbus' rounded nose vs Boeing's pointed nose

When an airplane is in the hypersonic range (> Mach 1) (mostly military aircrafts), they suffer a shock at the nose as they transition into a speed greater than that of sound. Thus, they need a pointed nose.

The nose cone models are constructed from existing references [20]. Two blunt nose profiles- elliptical and spherically blunted tangent ogive are commonly used in transonic commercial airplanes. These models are prepared with model to prototype ratio of 1:33. The models were constructed using the sketch and revolve command in NX 10.0 which is a CAD software by SIEMENS.

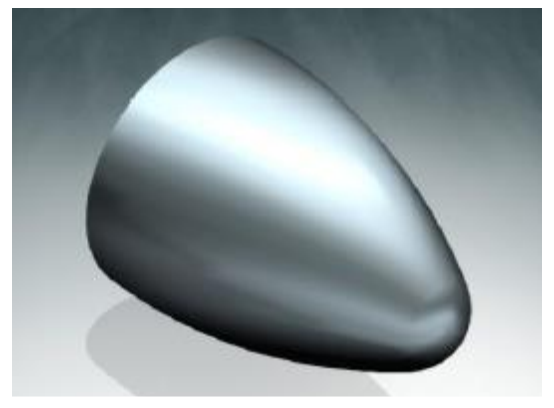

Fig. 2 CAD of the spherically blunted tangent ogive nose

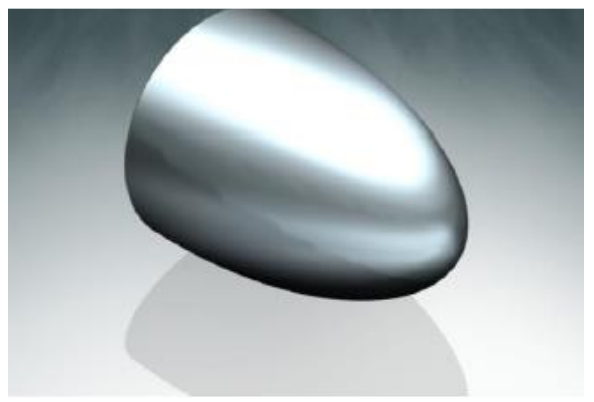

Fig. 3 CAD of the elliptical nose

\begin{tabular}{|c|c|c|}
\hline Dimensions & $\begin{array}{c}\text { Spherically } \\
\text { Blunted Tangent } \\
\text { Ogive }\end{array}$ & Elliptical \\
\hline Height (mm) & 120 & 120 \\
\hline Radius (mm) & 50 & 50 \\
\hline $\begin{array}{c}\text { Thickness } \\
\text { (mm) }\end{array}$ & 5 & 5 \\
\hline
\end{tabular}

Published By:

Blue Eyes Intelligence Engineering

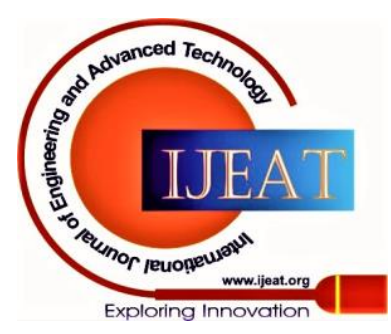


Discretization of the model- The CAD models are discretized or meshed to get numerical solutions. These were meshed with refinement at areas near the tip of the nose. The better the mesh of a model is, the better results are calculated.

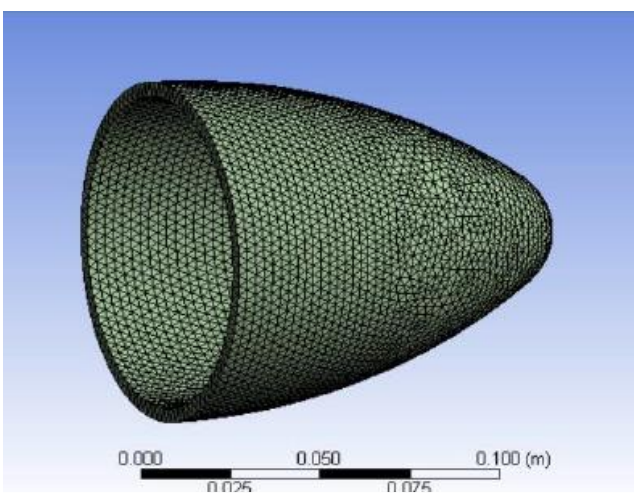

Fig. 4 Meshed model of the spherically blunted tangent ogive nose

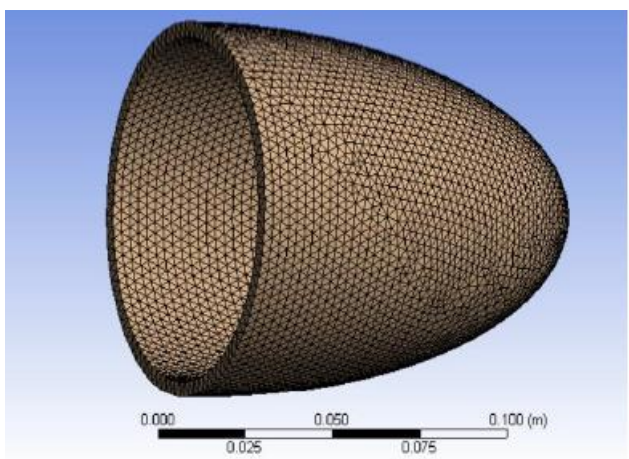

Fig. 5 Meshed model of the elliptical nose

\section{COMPUTATIONAL FLUID DYNAMICS}

CFD is an analysis tool to predict what happens when fluids flow and the stresses and displacements in a body which is surrounded by the fluid. The above CAD models were imported and analysed in ANSYS R18.1 Fluent which is a tool for CFD. It helped us in determining the drag and lift coefficients and the velocity and pressure contours when the boundary conditions such as wall attributes and inlet velocity was set at $10 \mathrm{~m} / \mathrm{s}$ (according to the model to prototype ratio).

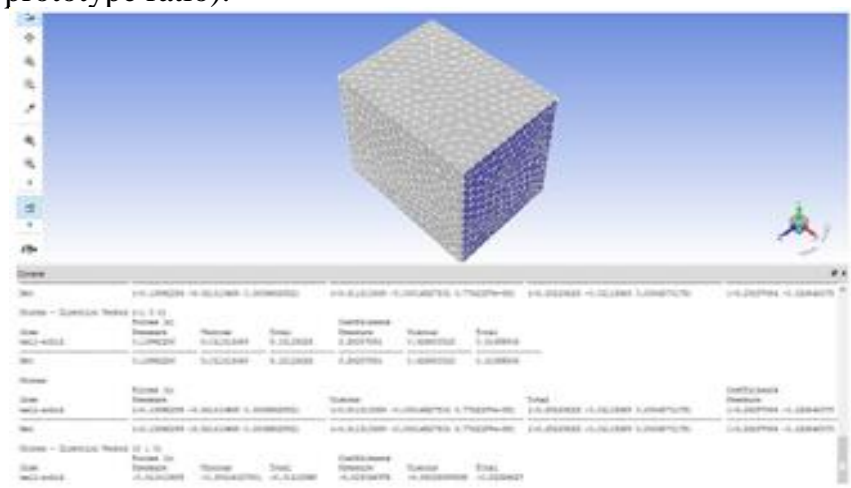

Fig. 6 Forces on the spherically blunted tangent ogive nose

\section{Table II Drag Forces on Nose}

\begin{tabular}{|c|c|}
\hline Nose & Drag Force (N) \\
\hline $\begin{array}{c}\text { Spherically Blunted Tangent } \\
\text { Ogive }\end{array}$ & 0.139 \\
\hline Elliptical & 0.138 \\
\hline
\end{tabular}

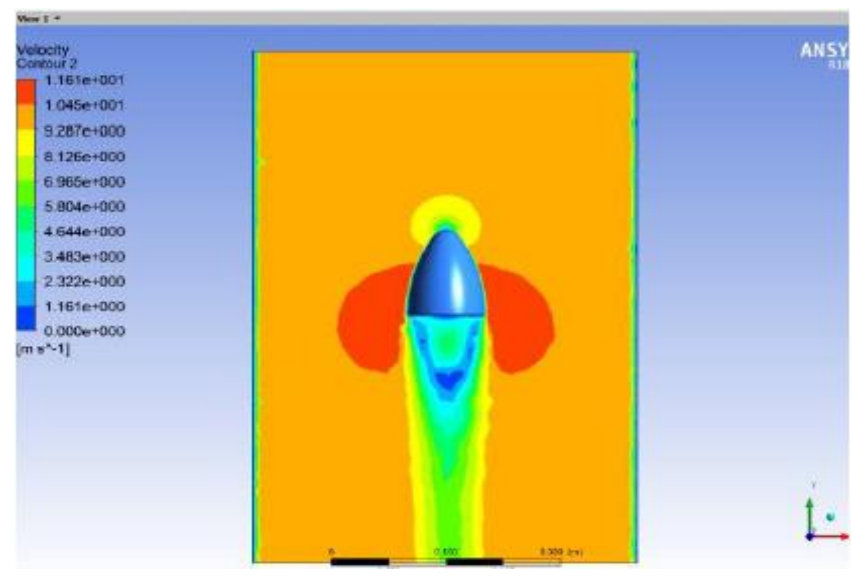

Fig. 8 Velocity contour of the spherically blunted tangent ogive nose

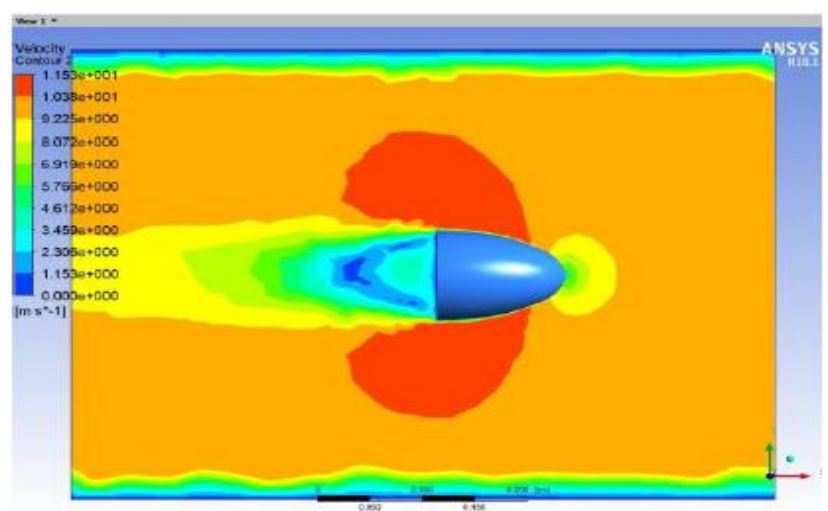

Fig. 9 Velocity contour of the elliptical nose riahts reserved.

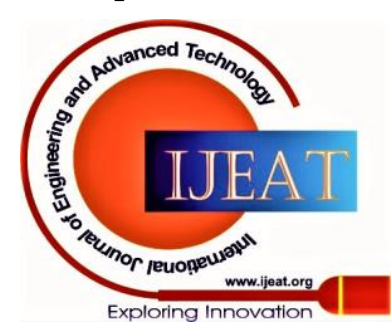




\section{Crash Analysis of Aircraft Nose Prototype}

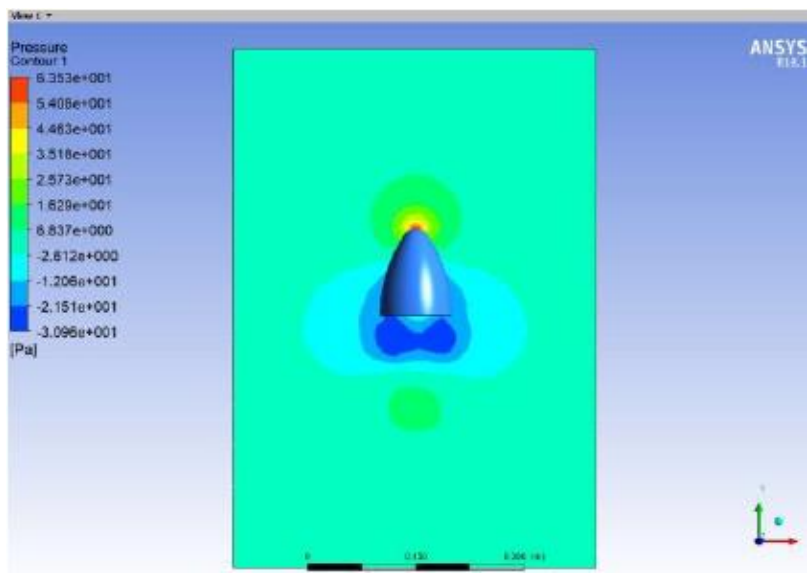

Fig. 10 Pressure contour of the spherically blunted tangent ogive nose

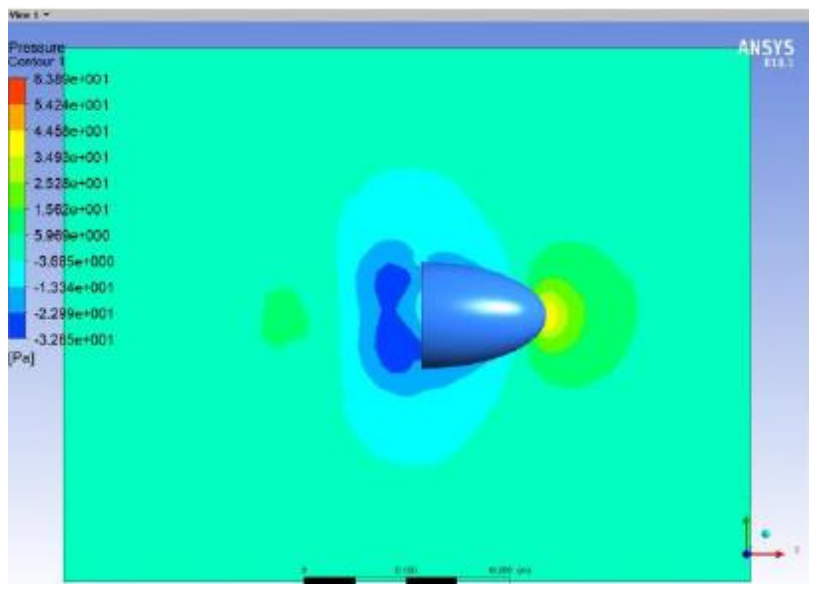

Fig. 11 Pressure contour of the elliptical nose

\section{EXPLICIT DYNAMICS}

Material Selection- More than four decades ago, aluminium ruled the aerospace industry. Various materials that have been used in the manufacturing of aircrafts since their advent are wood, steel, ceramics, silicon, carbide, titanium alloy, aluminium alloy and composites sandwiches, CFRP and metal fiber laminates. But in today's time, pure aluminium is not used as much as it would be used back then. The skin of an aircraft also depends upon the speed at which an aircraft is flying. Aircrafts having a hypersonic speed reach temperature up to $130^{\circ} \mathrm{C}$ which makes it difficult for many materials to sustain. Since aluminium is still used in aircraft structures, we studied properties of aluminium alloy and compared it to the properties of a composite material. The materials that we decided to assign to the nose cones are Aluminium Alloy 2024-T3 and CFRP (70\% carbon unidirectional fibers in epoxy matrix). These materials will be used in the crash analysis that will be performed in Ansys R 18.1 Explicit Dynamics.

Table III Material Properties

\begin{tabular}{|c|c|c|}
\hline Property & $\begin{array}{c}\text { Aluminium } \\
\text { Alloy 2024-T3 }\end{array}$ & CFRP \\
\hline $\begin{array}{c}\text { Tensile } \\
\text { Strength } \\
\text { (MPa) }\end{array}$ & 469 & $1500(\mathrm{LW})$ \\
& & $40(\mathrm{CW})$ \\
\hline
\end{tabular}

Published By:

Blue Eyes Intelligence Engineering and Sciences Publication (C) Copvriaht: All riahts reserved. the nose. nose nose

atmospheric pressure at $10 \mathrm{~m} / \mathrm{s}$. The structural steel plate $(260 \times 180 \times 20)$ was fixed while velocity was given to

a. Spherically Blunted Tangent Ogive Nose

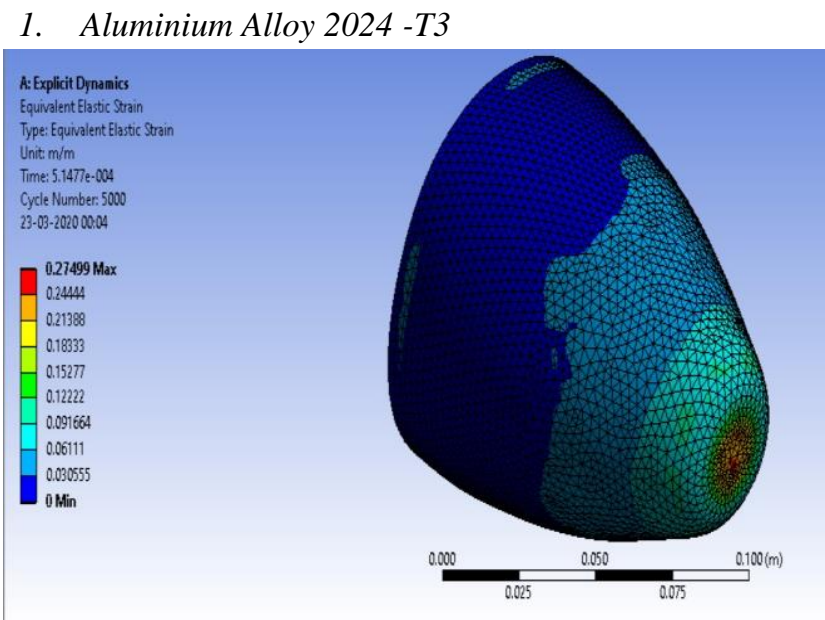

Fig. 12 Strain contour of the Al alloy spherically blunted

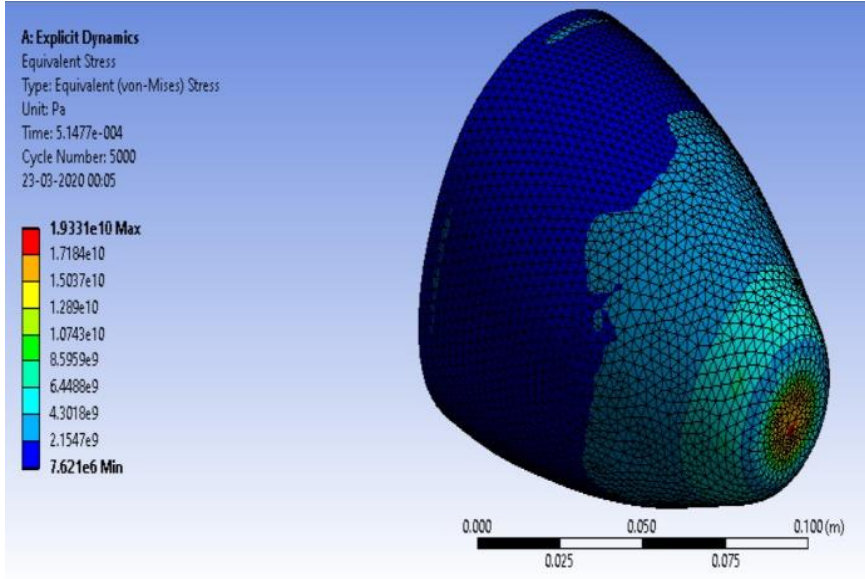

Fig. 13 Stress contour of the $\mathrm{Al}$ alloy spherically blunted

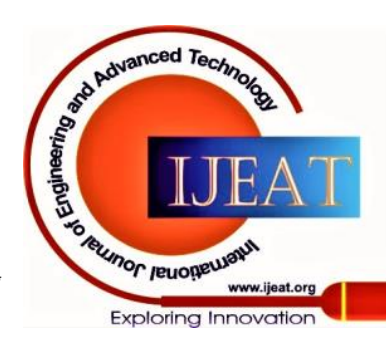




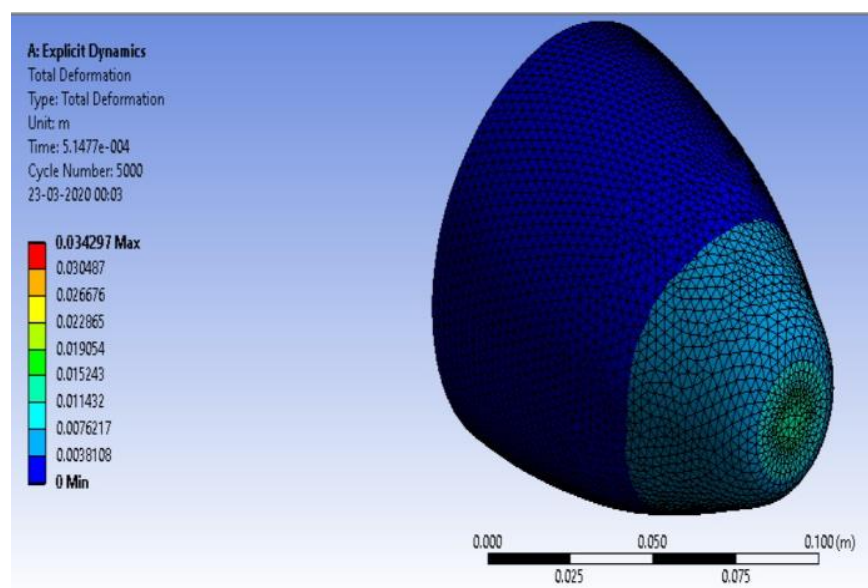

Fig. 14 Deformation contour of the Al alloy spherically blunted nose

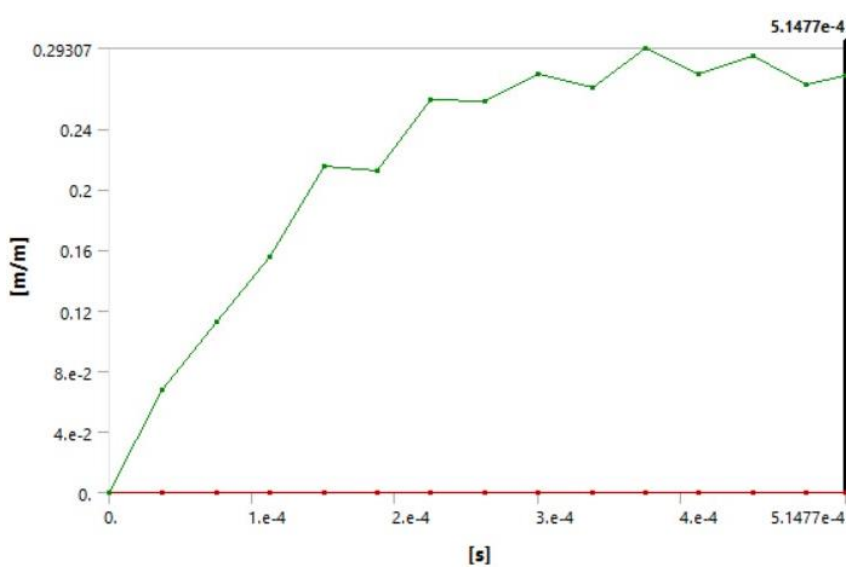

Fig. 15 Strain graph of the Al alloy spherically blunted nose

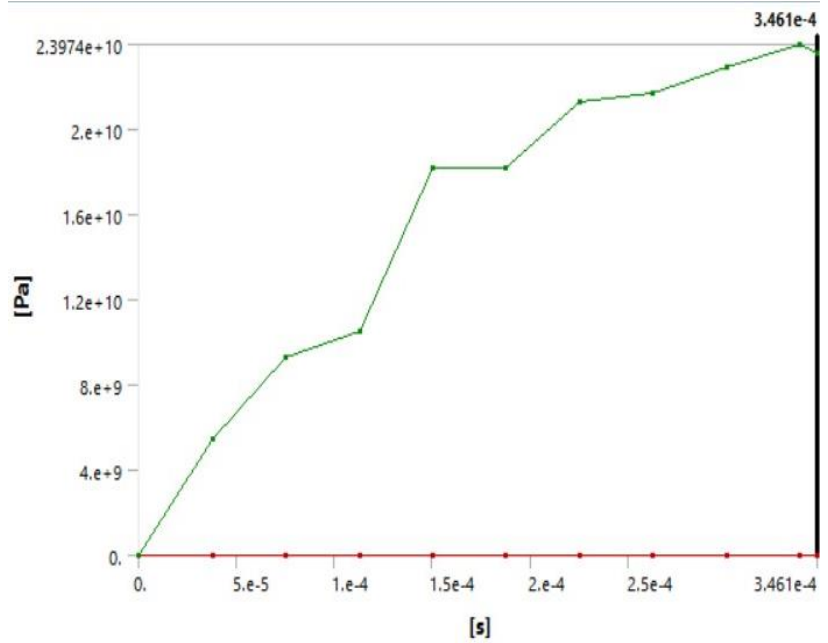

Fig. 19 Stress contour of the CFRP spherically blunted nose

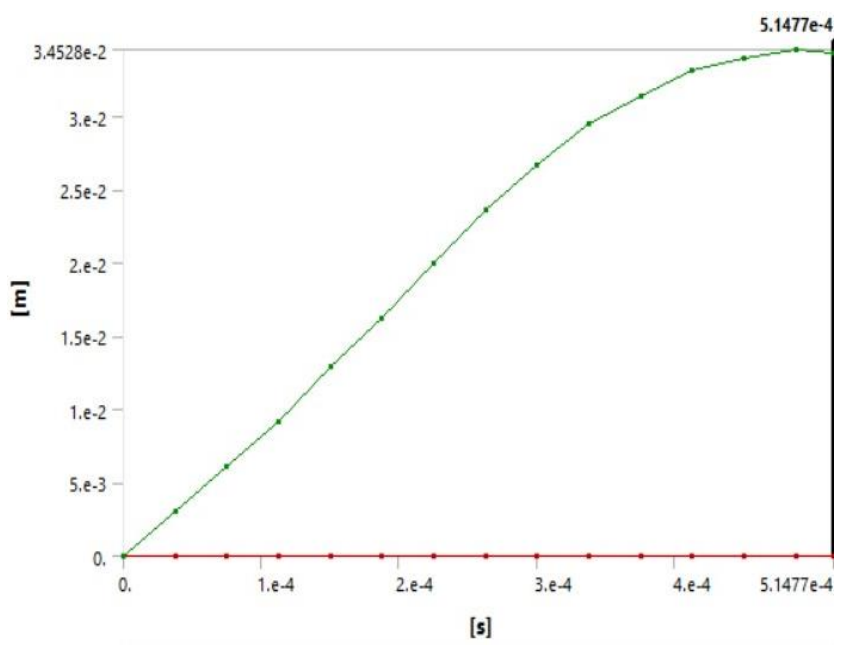

Fig. 17 Deformation graph of the Al alloy spherically blunted nose

2. Carbon Fibre Reinforced Polymer

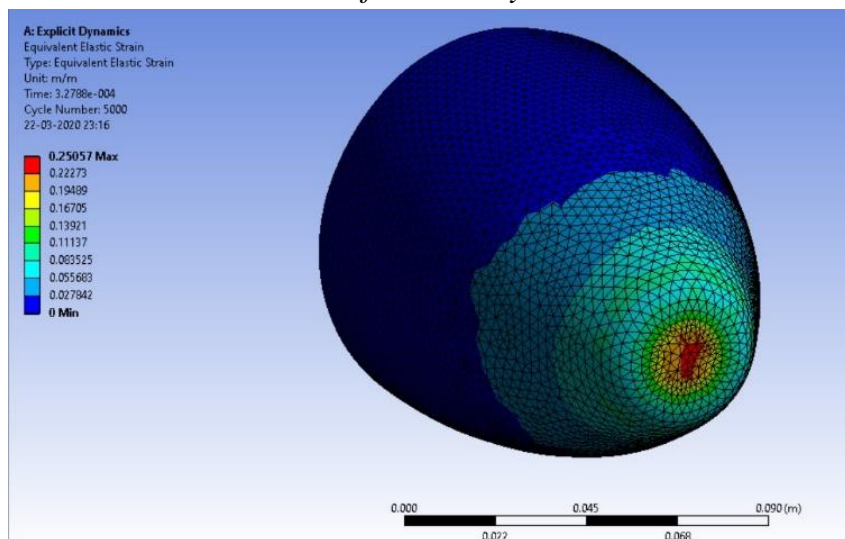

Fig. 18 Strain contour of the CFRP spherically blunted nose

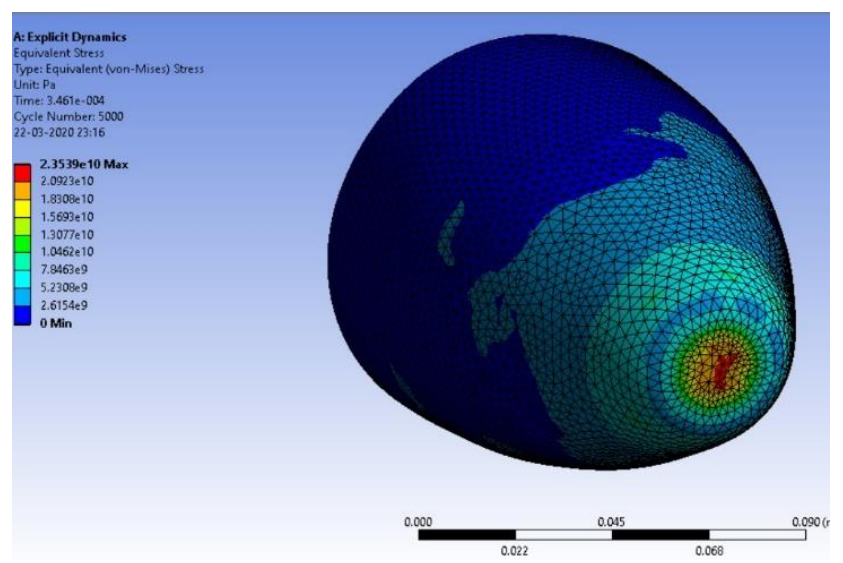

Fig. 16 Stress graph of the Al alloy spherically blunted nose

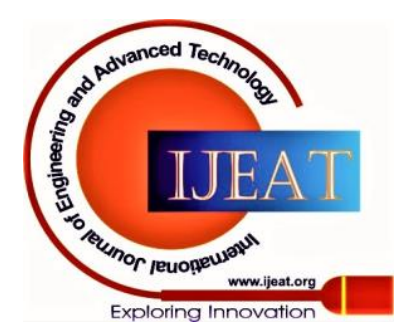




\section{Crash Analysis of Aircraft Nose Prototype}

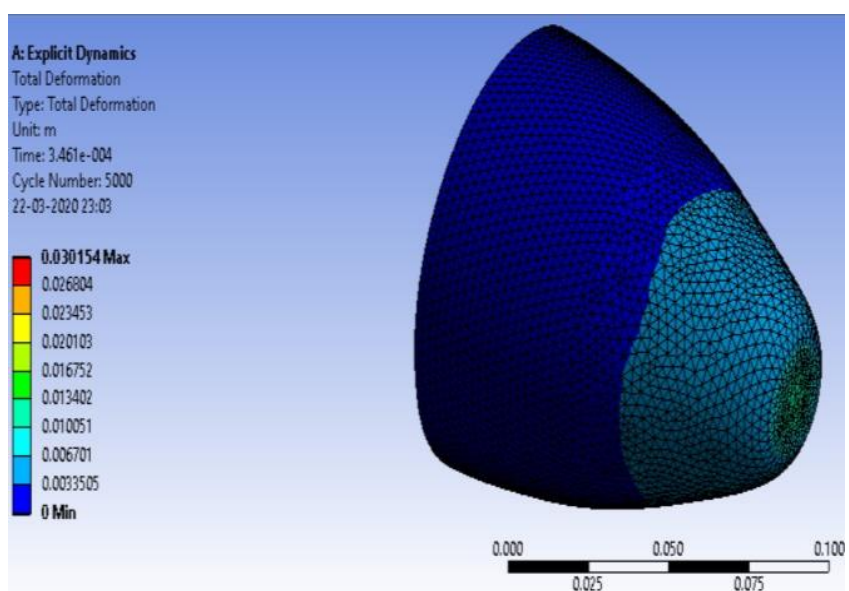

Fig. 20 Deformation contour of the CFRP spherically blunted nose

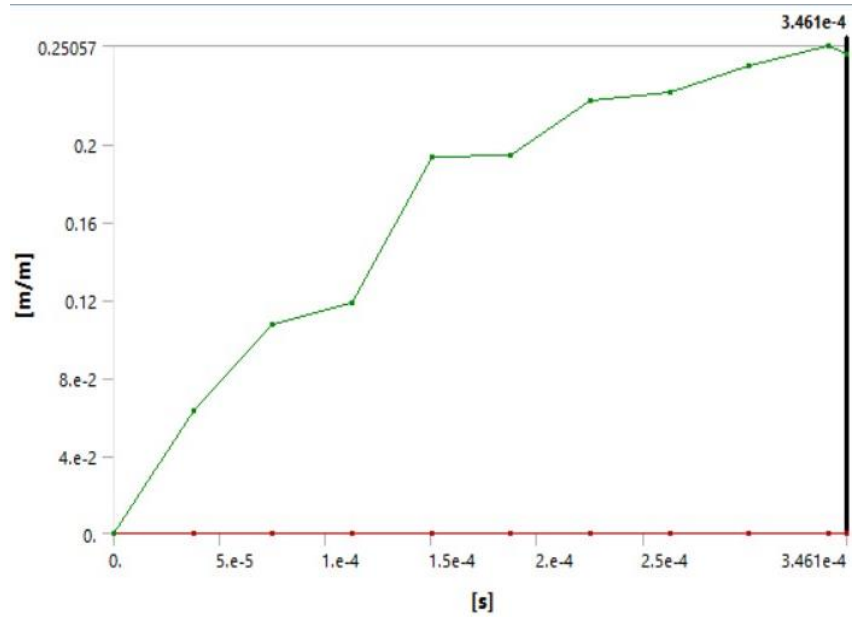

Fig. 21 Strain graph of the CFRP spherically blunted nose

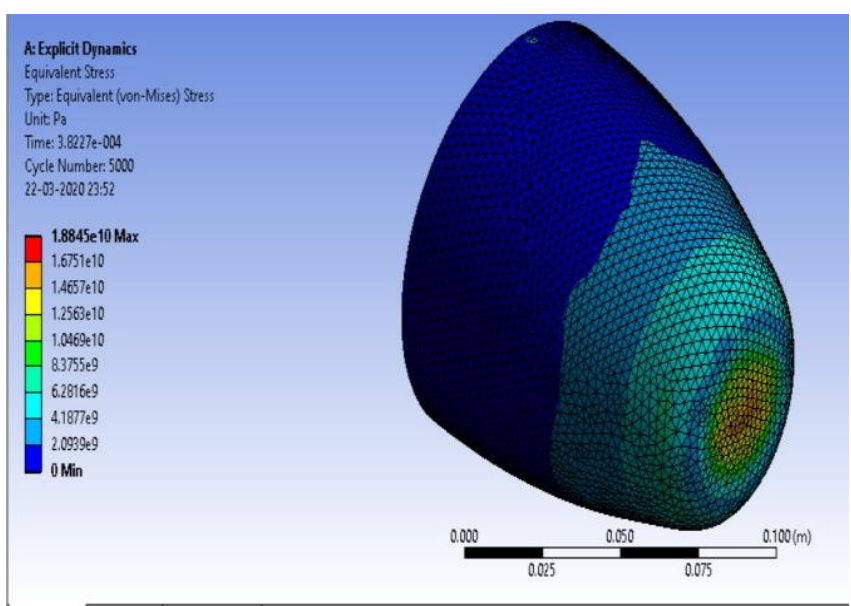

Fig. 22 Stress graph of the CFRP spherically blunted nose

Retrieval Number: F1360089620/2020@BEIESP

Published By:

Blue Eyes Intelligence Engineering and Sciences Publication

(C) Copvriaht: All riahts reserved.
Fig. 24 Strain Contour of the Al alloy elliptical nose

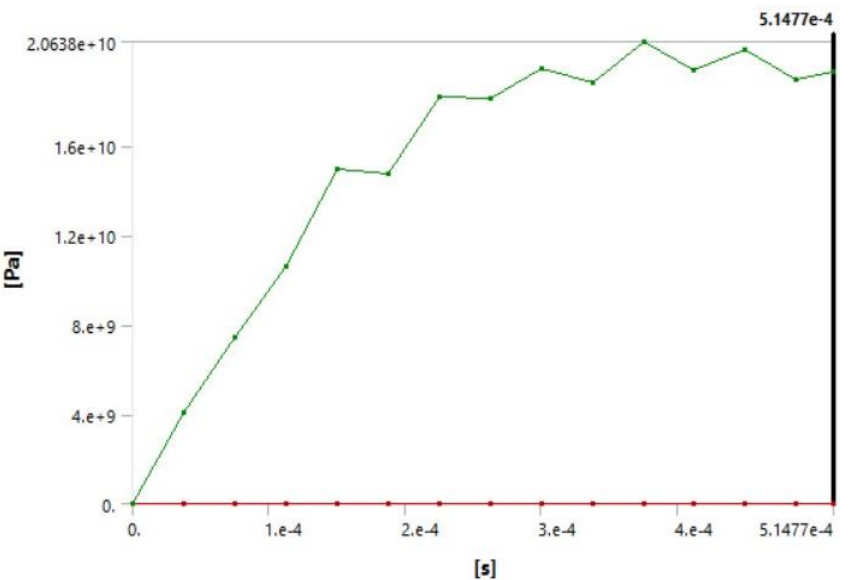

Fig. 25 Stress Contour of the Al alloy elliptical nose

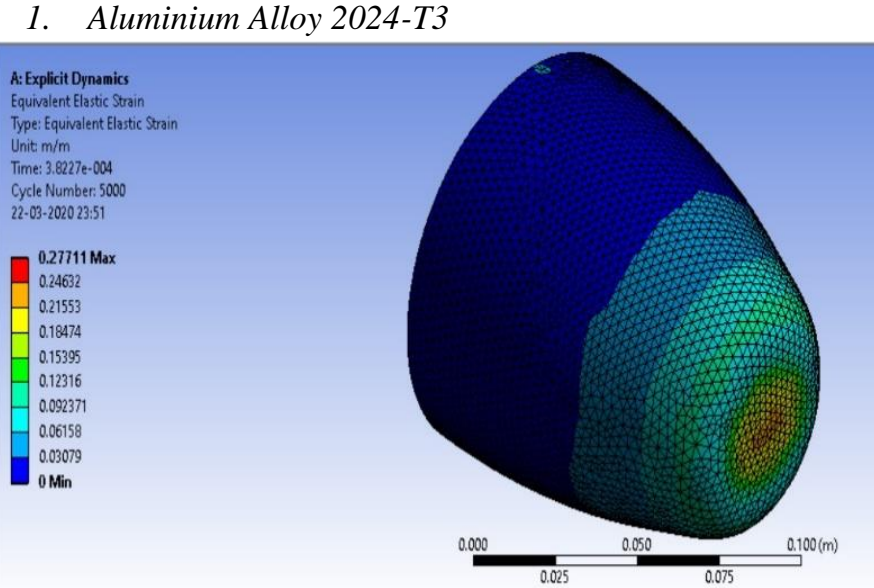




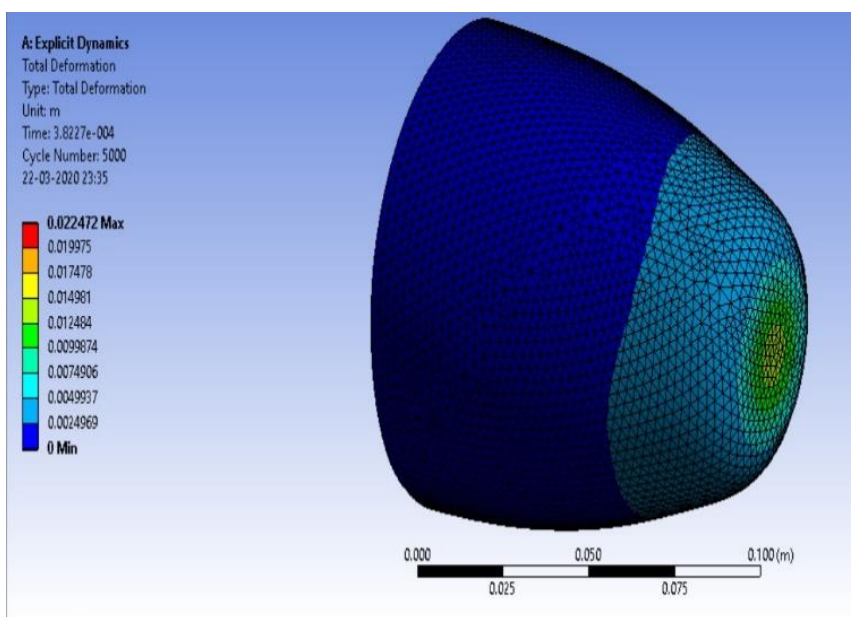

Fig. 26 Deformation Contour of the Al alloy elliptical nose

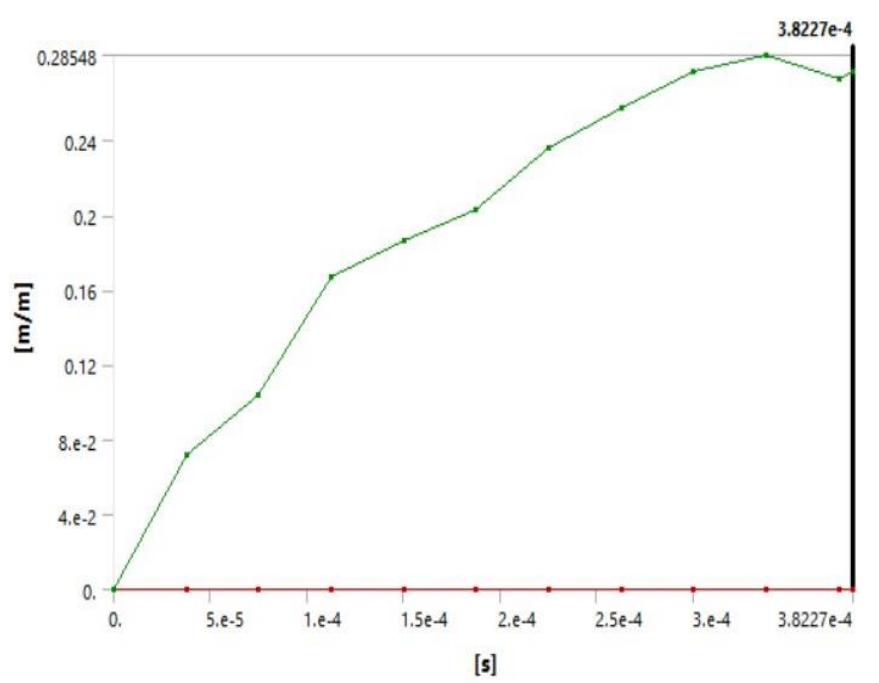

Fig. 27 Strain Graph of the Al alloy elliptical nose

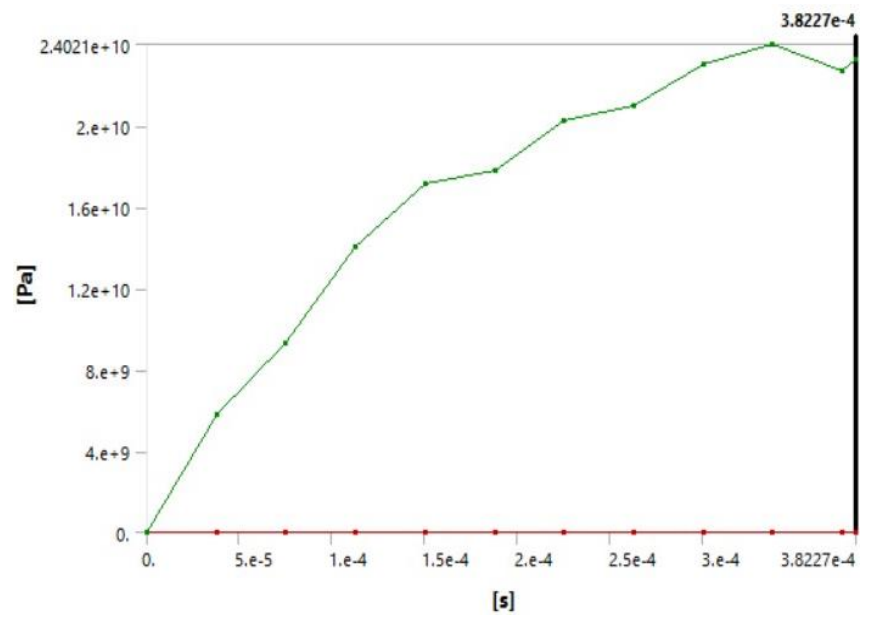

Fig. 28 Stress Graph of the Al alloy elliptical nose

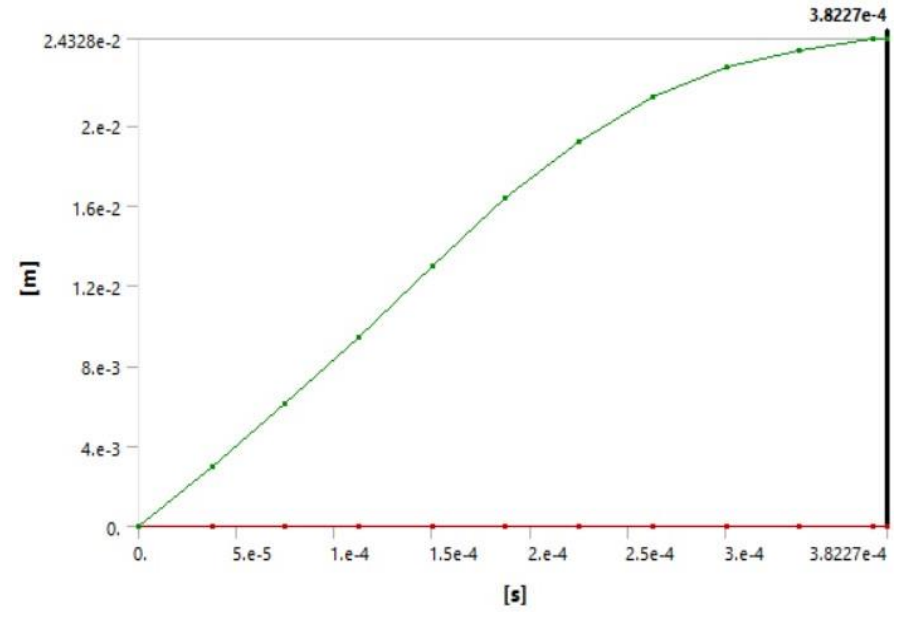

Fig. 29 Deformation Graph of the Al alloy elliptical nose

2. Carbon Fibre Reinforced Polymer

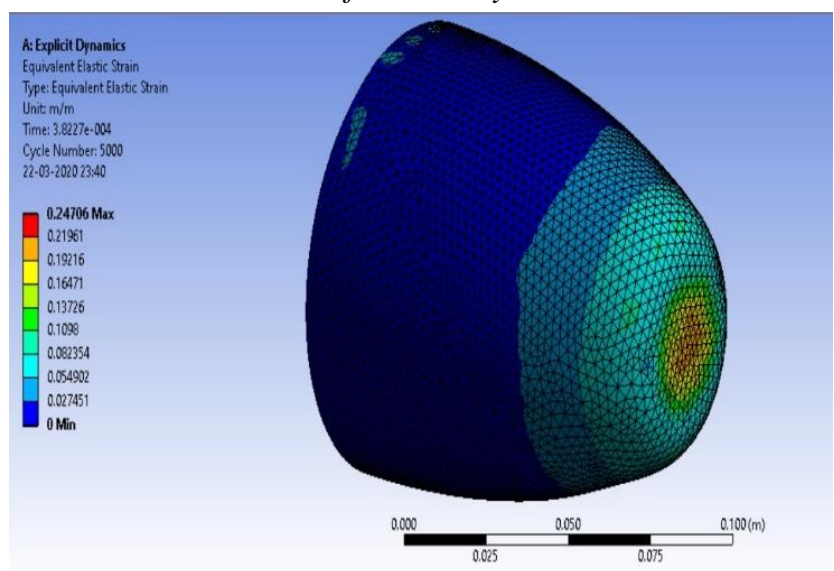

Fig. 30 Strain Contour of the CFRP elliptical nose

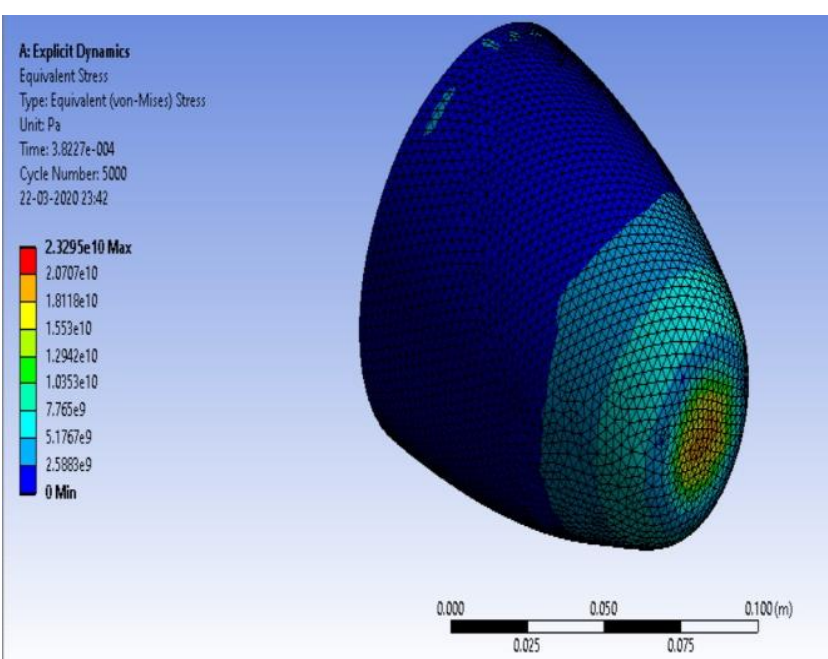

Fig. 31 Stress Contour of the CFRP elliptical nose

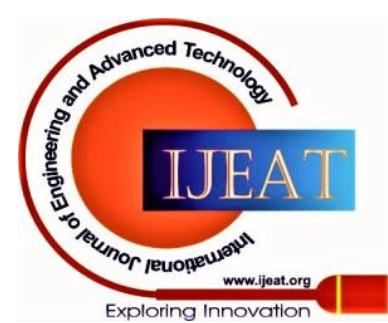




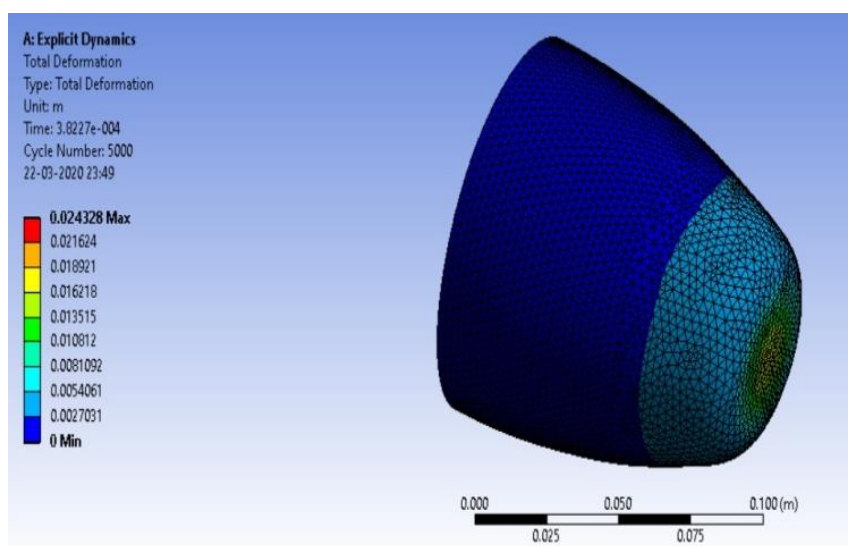

Fig. 32 Deformation Contour of the CFRP elliptical nose

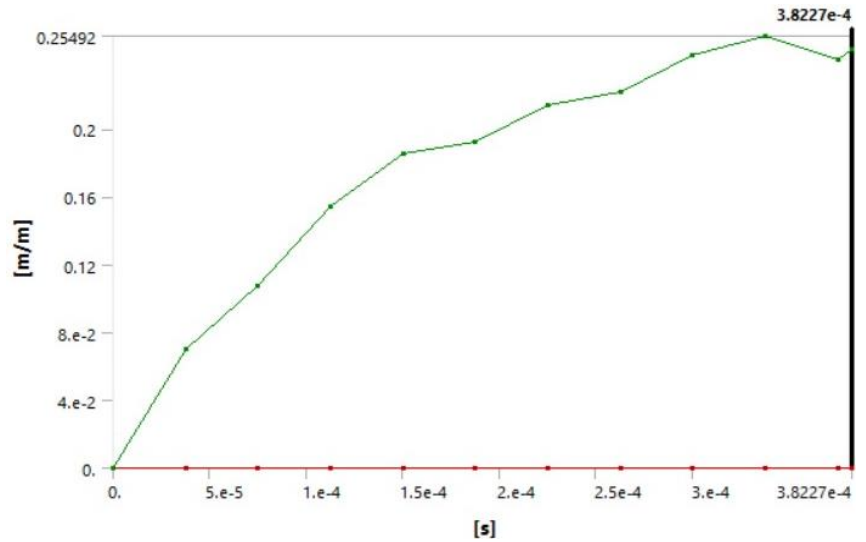

Fig. 33 Strain Graph of the CFRP elliptical nose

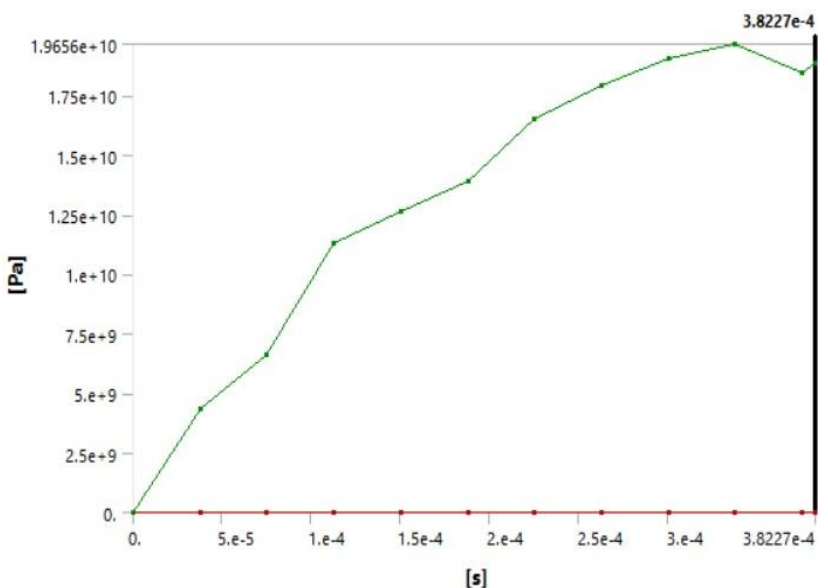

Fig. 34 Stress Graph of the CFRP elliptical nose

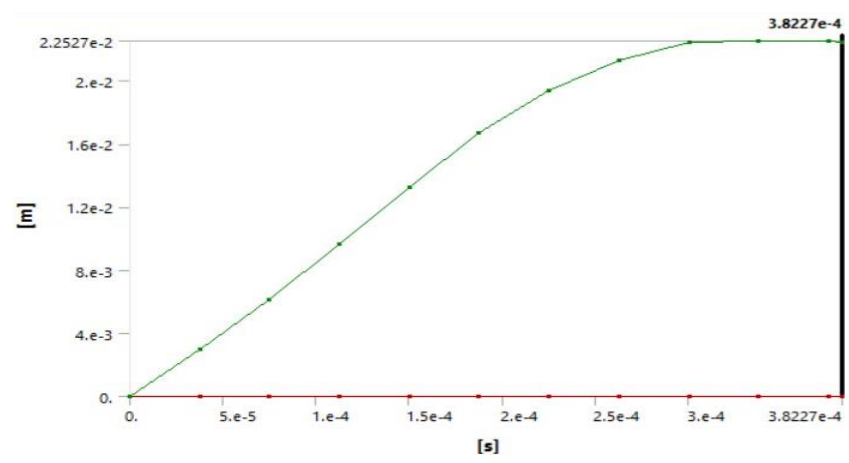

Fig. 35 Deformation Graph of the CFRP elliptical nose

\section{RESULTS AND DISCUSSIONS}

Table IV Results of CFD

\begin{tabular}{|c|c|c|}
\hline Property & $\begin{array}{c}\text { Spherically } \\
\text { Blunted }\end{array}$ & Elliptical \\
\hline $\begin{array}{c}\text { Pressure } \\
(\text { Pa) }\end{array}$ & 6.35 & 5.43 \\
\hline $\begin{array}{c}\text { Velocity } \\
(\mathrm{m} / \mathrm{s})\end{array}$ & 11.53 & 11.61 \\
\hline
\end{tabular}

From Fig 8, it is quite evident that the velocity (the red colour) on the circumference of the spherically blunted nose may be slightly higher than seen in Fig 9. But if seen carefully, the overall velocity $(=11.61 \mathrm{~m} / \mathrm{s})$ around the elliptical nose in Fig 9 is greater as there is more yellow colour which denotes higher velocity. In Fig 6.2.3, the tip of the spherically blunted tangent ogive shows a tint of blue colour which denotes very lower velocity $(=11.53 \mathrm{~m} / \mathrm{s})$. This is proof that as the velocity increases, the coefficient of drag decreases. The pressure is really high at the tip of the spherically blunted nose i.e. shown in red colour in Fig 10 whereas there is relatively lower pressure seen around the tip of the elliptical nose in Fig 11. This is because the area of the tip of the spherically blunted tangent ogive nose is lesser than the elliptical nose which supports the fact that blunt noses are a better choice for aircrafts. From this, we may conclude that the elliptical nose has a better design than spherically blunted tangent ogive nose due to its lower drag force.

Table V Results of Explicit Dynamics

\begin{tabular}{|c|c|c|c|c|}
\hline Property & \multicolumn{2}{|c|}{$\begin{array}{c}\text { Spherically } \\
\text { Blunted }\end{array}$} & \multicolumn{2}{c|}{ Elliptical } \\
& Al & CFRP & Al & CFRP \\
\hline Strain & 0.293 & 0.25 & 0.285 & 0.254 \\
\hline $\begin{array}{c}\text { Stress } \\
\left(\times \mathbf{1 0}^{\mathbf{1 0}} \mathbf{P a}\right)\end{array}$ & 2.397 & 2.063 & 2.402 & 1.9656 \\
\hline Deformation & 3.45 & 3.01 & 2.432 & 2.252 \\
$\left(\times \mathbf{1 0}^{-\mathbf{2}} \mathbf{~ m )}\right.$ & & & & \\
\hline
\end{tabular}

The lighter shades of blue are spread across more in $\mathrm{Al}$ Alloy nose which means that the stress, strain and deformation is higher than in CFRP nose. The strain in the $\mathrm{Al}$ alloy spherically blunted nose is 0.293 as seen in Fig 15 which is greater than the strain in CFRP nose which is 0.250 as seen in Fig 21. This graph predicts that if ever an aircraft with a CFRP nose crashes, it will undergo lesser change across the area than an $\mathrm{Al}$ Alloy as it will resist loading more than the other. The stress in the Al alloy nose is $2.397 \times 10^{10} \mathrm{~Pa}$ as seen in Fig 16 which is greater than the stress in CFRP nose which is $2.063 \times 10^{10} \mathrm{~Pa}$ as seen in Fig 22. Since the Tensile Strength of CFRP is higher, this graph predicts that if an airplane with a CFRP nose crashes, lesser impact stresses will be produced when compared to an $\mathrm{Al}$ Alloy nose.

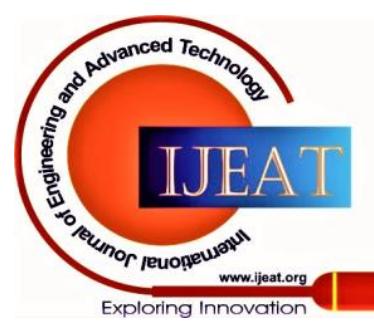


The deformation in the $\mathrm{Al}$ alloy nose is $3.45 \times 10^{-2} \mathrm{~m}$ as seen in Fig 17 which is greater than the deformation in CFRP nose which is $3.01 \times 10^{-2} \mathrm{~m}$ as seen in Fig 23. As can be seen in the graphs and contours, the shape of the CFRP nose of an aircraft is less deformed than an Al Alloy nose when it crashes. The strain in the Al alloy elliptical nose is 0.285 as seen in Fig 27 which is greater than the strain in CFRP nose which is 0.254 as seen in Fig 33. This graph predicts that if ever an aircraft with a CFRP nose crashes, it will undergo lesser change across the area than an Al Alloy as it will resist loading more than the other. The stress in the $\mathrm{Al}$ alloy nose is $2.402 \times 10^{10} \mathrm{~Pa}$ as seen in Fig 28 which is greater than the stress in CFRP nose which is $1.9656 \times 10^{10} \mathrm{~Pa}$ as seen in Fig 34. Since the Tensile Strength of CFRP is higher, this graph predicts that if an airplane with a CFRP nose crashes, lesser impact stresses will be produced when compared to an Al Alloy nose. The deformation in the $\mathrm{Al}$ alloy nose is $2.432 \times 10^{-2} \mathrm{~m}$ as seen in Fig 29 which is greater than the deformation in CFRP nose which is $2.252 \times 10^{-2} \mathrm{~m}$ as seen in Fig 35 . As can be seen in the graphs and contours, the shape of the CFRP nose of an aircraft is less deformed than an Al Alloy nose when it crashes. The properties of CFRP have contributed to the lesser deformation of the nose profiles. It can be concluded that composites have a higher strength than metals. From the above contour plots and graphs, it is evident that the deformation is more in spherically blunted tangent ogive nose rather than the elliptical nose as it is less blunt than the other. Carbon fiber is a material that offers stiffness and strength at low density- which is lighter than aluminium and steel that provides many practical benefits.

\section{CONCLUSION}

This analysis has been conducted to draw a comparison between the materials and shape characteristics assigned to the nose of an aircraft. According to the CFD results, the elliptical nose has an upper hand because of the lower drag coefficient, better velocity contours and lesser pressure distribution around the nose. It can be inferred that commercial airplanes with Mach 1 or lesser should preferably have blunt nose tips. On exploring the crash impact of these nose cones, we have can conclude that carbon fiber reinforced polymer when compared to aluminium alloy shows a lesser deformation and stress generated within it. It is due to the higher tensile strength of the composite. As is seen, the density of this composite is lesser than the metal alloy which reduces the overall weight of the aircraft and the fuel consumption. Thus, it can be concluded that airplanes should employ the use of composite materials and more blunt noses to make them more crashworthy ensuring the safety of all the communication systems that it houses. Fiber metal laminates like glass laminate aluminium reinforced epoxy are lightweight and are being tested on aerospace structures. These materials have improved impact resistance and are turning out to be more damage tolerant.

\section{FUTURE SCOPE:}

1. A detailed study on the impact of a crash on the communication systems with loads on individual component could be carried out.

2. More materials like metal-fiber laminates and advanced composites should be explored for analysing an airplane structure.
3. A more efficient nose profile can be derived from existing designs or a new can be designed for analysis.

4. Softwares which have sophisticated crash codes like LSDyna, MSC Dytran and Radioss could be used to achieve accurate results.

5. Various tests on the Universal Testing Machinecompression, tensile and shear and charpy tests could be conducted on the material.

6. Scanning Electron Microscope and Transmission Electron Microscope imaging of the materials could be done to have a more educated approach towards the material to study its composition and topography.

\section{REFERENCES}

1. Caliskan, A. G. (2002). Design \& analysis of composite impact structures for formula one using explicit FEA techniques. SAE Transactions

2. Fasanella, E. L., Jackson, K. E., \& Lyle, K. H. (2002). Finite element simulation of a full-scale crash test of a composite helicopter. Journal of the American Helicopter Society, 47(3), 156-168.

3. Bossak, M., \& Kaczkowski, J. (2003). Global/local analysis of composite light aircraft crash landing. Computers \& structures, 81(811), 503-514.

4. Jackson, K. E., \& Fasanella, E. L. (2003). Test-analysis correlation of a crash simulation of a vertical drop test of a commuter-class aircraft. In The Fourth Triennial International Aircraft Fire and Cabin Safety Research Conference, Lisbon, Portugal.

5. Botelho, E. C., Silva, R. A., Pardini, L. C., \& Rezende, M. C. (2006). A review on the development and properties of continuous fiber/epoxy/aluminum hybrid composites for aircraft structures. Materials Research, 9(3), 247-256.

6. Arros, J., \& Doumbalski, N. (2007). Analysis of aircraft impact to concrete structures. Nuclear engineering and design, 237(12-13), 1241-1249.

7. Tarpani, J. R., Maluf, O., \& Gatti, M. C. A. (2009). Charpy impact toughness of conventional and advanced composite laminates for aircraft construction. Materials Research, 12(4), 395-403.

8. Zhou, M., Patten, S., Kemp, M., Yancey, R., Mestres, E., \& Mouillet, J. B. (2011). Applications of Advanced Composite Simulation et Design Optimization. Altair Engineering.

9. Zhenyu, F., Peng, H., \& Tianchun, Z. (2011). Research development of crashworthiness simulation evaluation on civil aircraft. Procedia Engineering, 17, 286-291.

10. Ajayi, J. A., Joseph, O. O., \& Oloruntoba, D. T. (2013). Experimental failure investigation of an Aircraft Nose Landing gear. International Journal Metallurgical \& Materials Science and Engineering (IJMMSE), 3(1), 85-92.

11. Liu, X., Guo, J., Bai, C., Sun, X., \& Mou, R. (2015). Drop test and crash simulation of a civil airplane fuselage section. Chinese Journal of Aeronautics, 28(2), 447-456.

12. Suresha, P. V., Ayyappaa, K., Kumaria, V. A., Koteswararaoa, M., \& Venumurali, J. (2015). Design of an Air Craft Nose Cone and Analysis of Deformation under the Specified Conditions with Different Materials using ANSYS.

13. Fasanella, E. L., \& Jackson, K. E. (2016). Crash testing and simulation of a Cessna 172 aircraft: pitch down impact onto soft soil.

14. Mahantayya KHiremath, Somashekar V (2016). Crash Analysis of Unmanned Aerial Vehicle Using FEA. International Journal of Innovative Research in Science,Engineering and Technology, Vol. 5

15. Sun, G., Li, S., Liu, Q., Li, G., \& Li, Q. (2016). Experimental study on crashworthiness of empty/aluminum foam/honeycomb-filled CFRP tubes. Composite Structures, 152, 969-993.

16. Jeevanantham, V., Vadivelu, P., \& Manigandan, P. (2017). Material Based Structural Analysis of a Typical Landing Gear.

17. Chen, P. W., \& Lin, Y. Y. (2018). Evaluation on crashworthiness and energy absorption of composite light airplane. Advances in mechanical engineering, 10(8), 1687814018794080.

18. Jun, L. I. U., Yulong, L. I., Xiancheng, Y. U., Xiaosheng, G. A. O., \& Zongxing, L. I. U. (2018). Design of aircraft structures against threat of bird strikes. Chinese Journal of Aeronautics, 31(7), 1535-1558.

\section{Published By:}

Blue Eyes Intelligence Engineering

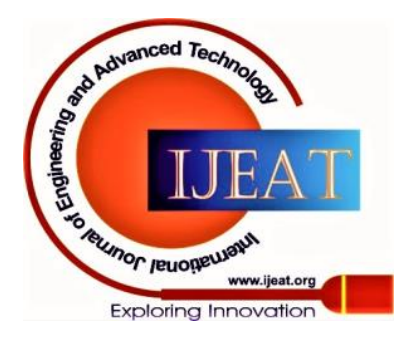




\section{Crash Analysis of Aircraft Nose Prototype}

19. Li, Z., Chen, R., \& Lu, F. (2018). Comparative analysis of crashworthiness of empty and foam-filled thin-walled tubes. Thinwalled structures, 124, 343-349.

20. Yeshwanth. A, Senthiil. PV (2018). Nose Cone Design And Analysis Of An Avion. International Journal of Pure and Applied Mathematics, Volume 119

21. Johnson, A. F., Thomson, R. S., David, M., Joosten, M. W., \& Waimer, M. (2020). Design and testing of crashworthy aerospace composite components. In Polymer Composites in the aerospace industry (pp. 371-414). Woodhead Publishing.

22. John G., (2007). World of Forensic Science, Reference Reviews, 21, 42-43.

\section{AUTHOR'S PROFILE}

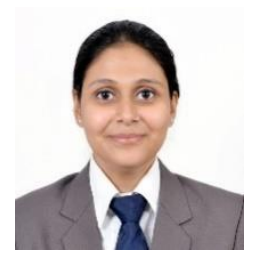

Adeeba Shaheen received her B.Tech degree in Mechanical Engineering from Symbiosis Institute of Technology, Symbiosis International (Deemed) University, Pune in 2020. This will be her first published article and is keen on researching in the field of materials in the aerospace domain. She has gained a week's training in DRDO, Chennai and completed a six month internship at 512 Army Base Workshop, Pune. She holds a Green Belt Lean Six Sigma Certification and plans to pursue her M.S. in Materials Science.

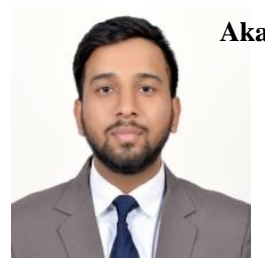

Akash Deep Sinha received his B.Tech degree in Mechanical Engineering from Symbiosis Institute of Technology, Symbiosis International (Deemed) University, Pune in 2020. This will be his first published article and is keen to work on CAE. He worked as a quality intern at Kailash Vahan Udyog Limited, TATA Pune and completed a six month internship at 512 Army Base Workshop, Pune. He holds a Green Belt Lean Six Sigma Certification and plans to pursue his M.S. in designing. He is currently an intern at Unified 3D Global Solutions.

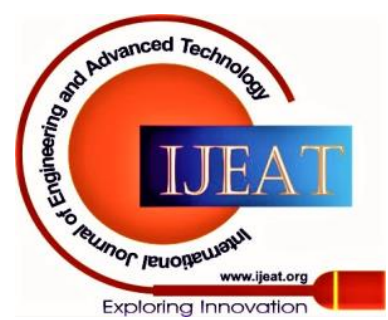

